\title{
Surgical correction of pectus excavatum using a retrosternal bar
}

\author{
COSTAS G. SBOKOS, I.K.R. M c M I L LAN, \\ a n d C A R Y W. A K I N S \\ Wessex Cardiac and Thoracic Centre, Southampton
}

\begin{abstract}
Sbokos, C. G., McMillan, I. K. R., and Akins, C. W. (1975). Thorax, 30, 40-45. Surgical correction of pectus excavatum using a retrosternal bar. Pectus excavatum is a progressive congenital deformity for which surgical correction is an established procedure.

The method of correction using a stainless steel retrosternal bar to maintain the sternum elevated is, in our experience, the most successful procedure. Successful surgical correction usually requires resection of all deformed costal cartilages with transverse osteotomy of the anterior table of the sternum and internal fixation using a bar anterior to the rib cage but behind the sternum.

In the last 13 years 118 patients with this deformity have been evaluated and 72 patients have been surgically corrected by the described procedure. Of these 72 patients, $65(90 \%)$ have had excellent or good cosmetic and functional results. The best results were obtained when the child was operated on between the ages of 6 and 10 years, the poorest results in those operated on under the age of 3 or over the age of 20 . For a satisfactory result the bar must be left in for at least six months; the best results were obtained in those patients in whom the bar was left in for at least one year. No serious complications have followed the use of this technique.
\end{abstract}

Pectus excavatum, considered to be a congenital chest deformity, is a disturbing abnormality for many children and their parents. The condition is manifested by a depression of the sternum, which is maximal at its junction with the xiphoid process. There is marked angulation of the ribs and very often associated skeletal changes such as scoliosis or kyphosis (Fig. 1). A protuberant abdomen is common.

Considerable disagreement has arisen about the aetiology of this abnormality, and its pathogenesis remains obscure. Brodkin (1953) and Chin (1957) favoured a diaphragmatic origin of the deformity, suggesting that it is due to a foreshortening of the central tendon of the diaphragm, pulling the sternum backwards with each inspiration. Mullard (1967) postulated the failure of osteogenesis and chondrogenesis of the anterior chest wall as the responsible factor. Firm evidence to support either theory is lacking.

Most patients and their parents understand the problem as primarily one of appearance, though they often worry about possible respiratory and physiological disturbances. Pectus excavatum is usually asymptomatic in childhood, but a de pressed sternum is capable of producing physio logical embarrassment of the heart and lungs on exercise. The primary indication for surgicab intervention is, therefore, cosmetic but, in as number of cases, combined with some degree of respiratory difficulty. Parents very often com? plain that the child has frequent respiratoryo infections and is less active than children of the same age at school. Attempts to expressos these symptoms quantitatively are very difficult as they may well be entirely subjective. Howfu ever, there is almost always an improvement in the activity of the patient following a successfuk correction.

One of the controversial aspects of the surgical correction of the pectus excavatum deformity is the method used to maintain sternal elevation a5 the completion of the correction. The purpose of this paper is to present a technique for operative correction of pectus excavatum using a stainless steel retrosternal bar for fixation, to assess the 


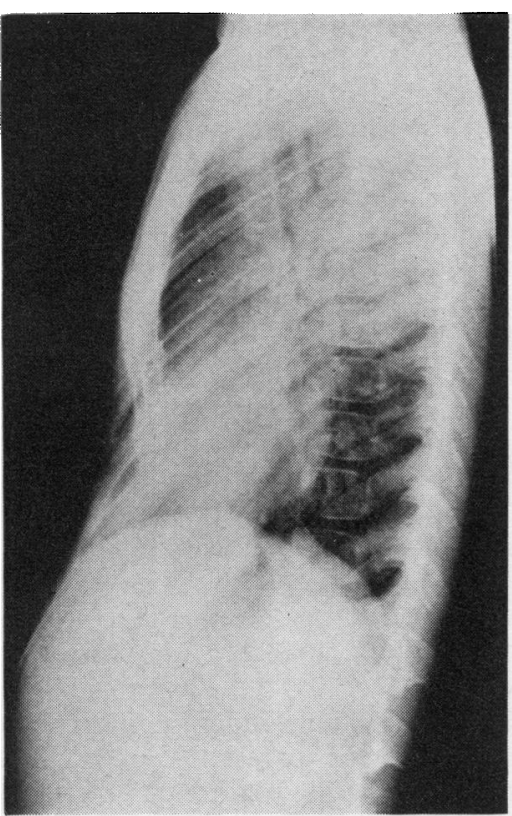

FIG. 1. Lateral chest radiograph to show typical pectus excavatum defect.

long-term results, and to discuss the possible factors predisposing to failure or recurrence.

\section{CLINICAL MATERIAL AND METHODS}

In the Thoracic Surgical Unit of the Southampton Western Hospital, 118 patients with funnel chest were evaluated between the years 1961 and 1973. Of these 118 patients, 72 underwent initial surgical correction and three had a second operation for correction of a recurrent deformity. Three additional patients had second corrections performed after failure of a first operation by another technique. All of the patients operated on had severe or marked deformities which produced in $37(51 \%)$ some symptoms of respiratory disturbances. Those with mild deformities are not usually operated on and are not included in this study. Many children, especially infants, are observed in outpatients for a period of years before a decision is made whether the lesion is progressive and severe enough to justify operation. The indications for operation were (a) cosmetic and (b) cosmetic and physiological. Dyspnoea, easy fatiguability or palpitations were strong indications for operation. Fifty-one patients $(70 \%)$ were males. The youngest at operation was aged 30 months and the oldest 29 years.

Results were based mainly on cosmetic evaluation and were arranged into three groups:

Excellent-no residual deformity, minimal scar, and no subjective disability.
Good-mild degree of remaining deformity or some mild abnormality in the surgical scar.

Poor-frank recurrence of the deformity or unacceptable surgical scar.

Since there was no mortality in the series, morbidity alone was assessed: postoperative pneumothorax, bleeding, wound infections, substernal fluid collections, and pericardial effusions were recorded.

Follow-up ranged from one to 13 years, $60 \%$ of patients being followed for more than five years.

\section{TECHNIQUE}

There have been many satisfactory methods proposed for correction of the pectus excavatum deformity.

Many authors recommend rigid internal or external fixation of the sternum (Abrams, 1961; Adkins and Blades, 1961; le Roux, 1964; Moghissi, 1964), others describe stabilization of the corrected sternum with wire struts, (Peters and Johnson, 1964; Johnson, 1972) stainless steel mesh (May, 1961), transsternal fixation with metal struts (Borgeskov and Raahave, 1971), or no fixation at all (Ravitch, 1949 and 1965; Lam and Brinkman, 1959).

Wooler et al. (1969) excised the deformed cartilages, mobilized the sternum, and then sutured the pericardial sac into a central position, which, they believe, corrects the deformity.

Wada and Ikeda (1972) have developed the 'sternoturnover' procedure and later the 'funnel costoplasty' for repair of unilateral deep funnel chest.

Our experience has been that the use of a transverse retrosternal and antecostal stainless steel bar for fixation of the sternum produces the most satisfactory long-term results in the correction of pectus excavatum deformity.

A vertical or transverse submammary incision is made. It extends from the angle of Louis to below the xiphoid if it is longitudinal, or to about the level of the fifth costal cartilage if it is bilateral transverse.

The skin flaps are mobilized laterally as necessary, and the pectoralis major muscle is then freed to expose all the deformed cartilages.

The upper costal cartilages are resected subperichondrially to just beyond the site of angulation and the lower including perichondrium. The number varies with the severity of the deformity, and usually entails the third to the seventh cartilages on both sides.

The xiphoid process is then excised and any remaining attachments to the sternum are divided, freeing the sternum except for its junction with the manubrium. 
A transverse anterior osteotomy of the sternum is carried out at the level of the third costal cartilage. After satisfactory mobilization of the depressed sternum has been accomplished, a stainless steel bar is inserted behind the sternum and in front of the ribs, and fixed at each end with a catgut suture holding the sternum in a slightly overcorrected position. The bar may need bending to produce a correct repair (Figs 2-5).

The retrosternal space is drained to an underwater seal, which is put on continuous suction for the immediate postoperative period.

Simple closure, with approximation of the muscles, fascia, and skin, is then completed.

All patients receive antibiotic cover postoperatively.

Bar removal is accomplished under local or general anaesthesia, after a firm correction has been achieved, by simple gentle traction of the bar.

\section{RESULTS}

The technique for correction of pectus excavatum described above has been used in 72 patients as an initial repair during the past 13 years, and all were done by one of us (I.M.). Three of these patients required a second operation for correc- $\overline{\bar{\omega}}$. tion and three additional patients had a second $\overparen{\otimes}$ operation performed following failure of a first operation by another technique.

The deformity was identified in 56 of the $\overrightarrow{0}$ patients $(78 \%)$ before the age of 2 years, and in the remaining $16(22 \%)$ later in childhood (Table $\vec{\omega}^{\omega}$ I). A family history of pectus excavatum was $\vec{F}$ recorded in 21 cases $(26 \%)$. Ten of the patients $\times$ $(14 \%)$ had associated congenital anomalies, in- 0 cluding inguinal hernia, undescended testis, scoliosis, perforated nasal septum, atrial septal ${ }^{\circ}$ defect, Morgagni hernia, Hirschsprung's disease, 으 and absence of the pectoralis major muscle.

Of the 72 patients, $37(51 \%)$ gave a history of ${ }_{\mathbb{D}}^{7}$ dyspnoea on exertion, frequent colds, palpita- $\frac{O}{2}$ tions or inability to keep up with those of similar age.

The youngest patient undergoing correction was $\vec{\varphi}$ 30 months and the oldest 29 years. Follow-up or varied from one to 13 years, $60 \%$ of the patients

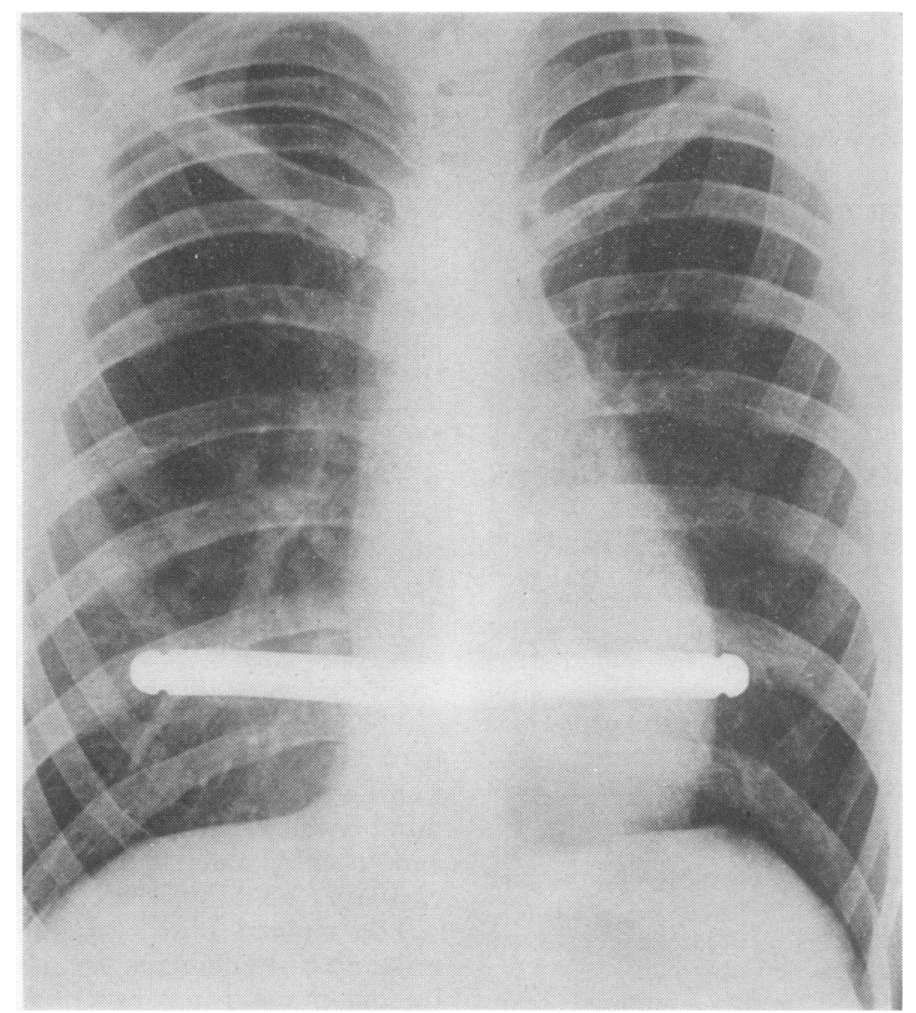

FIG. 2. Chest radiograph shows the bar in position. 


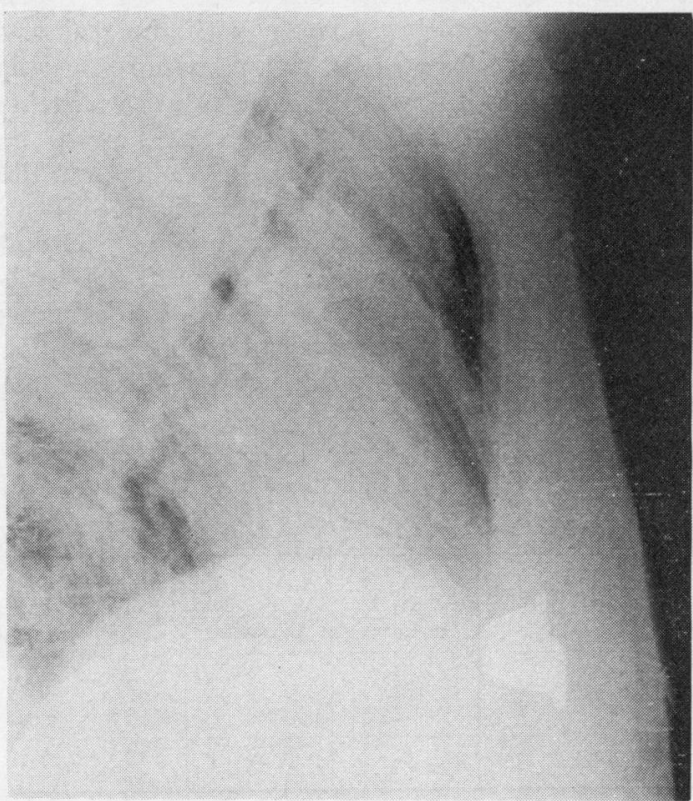

FIG. 3. Lateral film with the retrosternal bar in position. Note the bend in the bar.

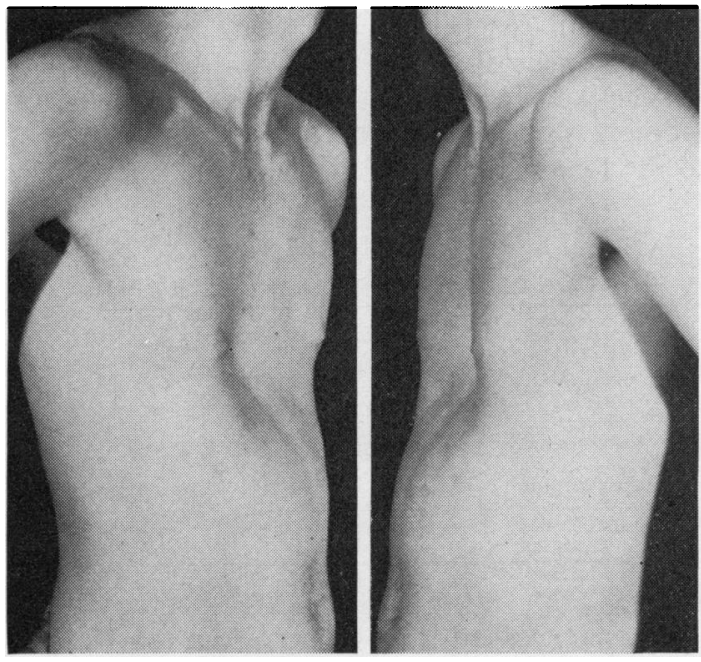

FIG. 4. Pectus excavatum before correction.

T A B L E I

AGE AT DIAGNOSIS

\begin{tabular}{l|c|c}
\hline Age (years) & $\begin{array}{c}\text { No. } \\
\text { of Cases }\end{array}$ & $\%$ \\
\hline Under 2 & 56 & 78 \\
$2-5$ & 13 & 18 \\
Over 5 & 3 & 4 \\
\hline Total & 72 & 100 \\
\hline
\end{tabular}
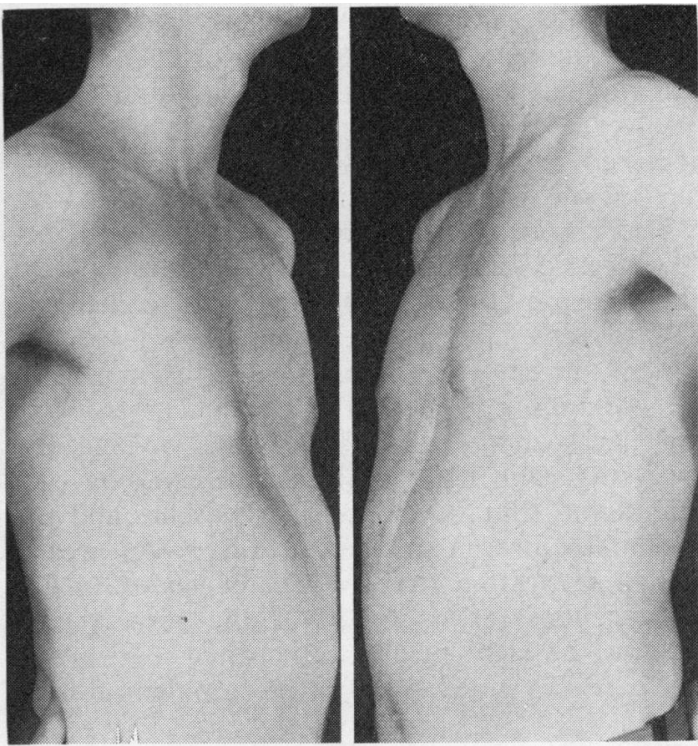

FIG. 5. Excellent result after surgical correction.

being followed for more than five years (Tables II and V).

T A B L E I I

RELATION OF AGE AT OPERATION TO LONG-TERM RESULTS

\begin{tabular}{c|c|c|c|c}
\hline \multirow{2}{*}{\begin{tabular}{c|c|c|} 
Age at Operation \\
(Years)
\end{tabular}} & $\begin{array}{c}\text { No. } \\
\text { of Cases }\end{array}$ & \multicolumn{2}{|c}{ Results } & \\
\cline { 4 - 5 } & Excellent & Good & Poor \\
\hline Under 3 & 6 & 2 & 2 & 2 \\
$3-5$ & 17 & 15 & 1 & 1 \\
$6-10$ & 23 & 23 & 0 & 0 \\
$11-20$ & 21 & 12 & 6 & 3 \\
Over 20 & 5 & 1 & 3 & 1 \\
\hline Total & 72 & 53 & 12 & 7 \\
& & &
\end{tabular}

Of the 37 patients who admitted to symptoms preoperatively, all had successful relief of their symptoms. Of the remainder who denied any symptoms, all admitted to a subjective improvement in their feeling of well-being.

Overall $53(73 \%)$ of the 72 patients achieved excellent cosmetic results, $12(17 \%)$ had good results, and seven $(10 \%)$ had poor results (Table V).

Of the seven patients judged to have poor results, four were clearly failures within three years after the operation (Table V). Of the seven failures, four were poor on the basis of frank recurrence of the lesion and all had the bar removed early, and three were failures because of an unacceptable scar. Only three of the seven 
poor results came to re-operation. An additional three failures of a first operation by another technique (not included in this study) also received a second correction, and all six patients achieved excellent or good results. In all cases the bar was removed without difficulty.

There were no deaths in the series. Six patients developed superficial wound infections, six required aspiration of substernal fluid collections, 12 had some degree of postoperative fever, one patient developed a pericardial effusion due to the bar falling between the ribs and pressing on the pericardium, and there were no bleeding problems. One child required the excision of a granuloma that developed in the scar, and one patient required a small skin graft to an area of wound separation that eventually healed to give an excellent result. In 20 of the surgical procedures the right pleura was opened, but in only one case was it necessary to insert a pleural drain.

\section{DISCUSSION}

Certainly many children with a pectus excavatum deformity have no symptoms, but over half will admit to some difficulty on careful questioning. The commonest symptoms were shortness of breath on exertion, frequent chest infections, palpitations on exercise or easy fatigability.

Of the patients with symptoms before the operation, all reported a resolution of these symptoms postoperatively, while those who denied any preoperative symptoms usually had an increased sense of well-being following the correction. We therefore consider that the physiological effect of the repair can be important.

From a cosmetic point of view most of the patients $(73 \%)$ reported excellent results and another $17 \%$ had good results. Examining the results in relation to age at operation (Table II), several things are clear: the younger the patient at the time of correction, provided he is at least 3 years of age, the better his chances are of an excellent cosmetic result. The optimum age for correction of pectus excavatum in our series seems to be between 6 and 10 years of age. If the patient is younger than 3 or older than 20 he has less chance of an excellent result; we tend to operate on patients at the extremes of age more for relief of symptoms than in the hope of an excellent cosmetic result (Haller et al., 1970).

Certain details of the technique merit emphasis. The xiphoid process was removed in $45(64 \%)$ of the cases, and the anterior table of the sternum was osteotomized transversely in all but two of the cases.
Stabilization of the sternum with the stainless steel retrosternal bar is of prime importance, as 듬 is the duration of fixation, for in those 13 patients $\frac{\overline{\bar{s}}}{2}$ in whom, for some reason, the bar had to be $\bar{\square}$ removed in less than six months following the correction, six developed poor results (Johnson,

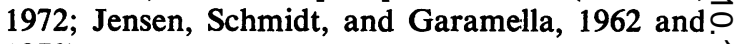
1970).

However, 30 out of 32 in whom the bar was left for longer than one year had excellent results, $\overrightarrow{\vec{x}}$ and the remaining two were good results (Table ${ }_{\omega}^{x}$ III).

\section{T A B L E I I I}

RELATION OF BAR REMOVAL TO LONG-TERM RESULTS

\begin{tabular}{|c|c|c|c|c|}
\hline \multirow{2}{*}{$\begin{array}{c}\text { Bar Removal } \\
\text { (months after } \\
\text { correction) }\end{array}$} & \multirow{2}{*}{$\begin{array}{c}\text { No. } \\
\text { of Cases }\end{array}$} & \multicolumn{3}{|c|}{ Results } \\
\hline & & Excellent & Good & Poor \\
\hline $\begin{array}{c}\text { Under } 6 \\
6-12 \\
12-38\end{array}$ & $\begin{array}{l}13 \\
27 \\
32\end{array}$ & $\begin{array}{r}2 \\
21 \\
30\end{array}$ & $\begin{array}{l}5 \\
5 \\
2\end{array}$ & $\begin{array}{l}6 \\
1 \\
0\end{array}$ \\
\hline Total & 72 & 53 & 12 & 7 \\
\hline
\end{tabular}

Correct bar position is a major factor in healing; if the bar is placed too far forward due to enthusiasm for perfect correction, it may cause $\stackrel{\circ}{\Omega}$ pressure necrosis of the skin.

Whether a transverse submammary or vertical $\stackrel{\overline{\vec{\sigma}}}{\vec{\partial}}$ incision was used seemed to make no difference $\frac{}{\sigma}$ to the long-term results (Table IV).

\section{T A B L E I V}

RELATION OF INCISION TO LONG-TERM RESULTS

\begin{tabular}{|c|c|c|c|c|}
\hline \multirow[b]{2}{*}{ Incision } & \multirow{2}{*}{$\begin{array}{l}\text { No. of } \\
\text { Cases }\end{array}$} & \multicolumn{3}{|c|}{ Results } \\
\hline & & Excellent & Good & Poor \\
\hline $\begin{array}{l}\text { Transverse } \\
\text { submammary } \\
\text { Vertical over } \\
\text { the sternum }\end{array}$ & $\begin{array}{l}45 \\
27\end{array}$ & $\begin{array}{l}32 \\
21\end{array}$ & $\begin{array}{l}9 \\
3\end{array}$ & $\begin{array}{l}4 \\
3\end{array}$ \\
\hline Total & 72 & 53 & 12 & 7 \\
\hline
\end{tabular}

Recurrences of the defect seem to develop gradually, and some of the early excellent results $N$ can become good or poor over the years (Borgeskov and Raahave, 1971; Haller et al.,o 1970). When a deformity does recur, however, it is usually evident within three years of the ${ }^{?}$ operation (Table V).

The technique seems equally applicable to $\stackrel{\vec{D}}{\vec{D}}$ patients who have had failure of a first correction, $\stackrel{\odot}{\stackrel{\odot}{\odot}}$ for all six of the patients coming to re-operation $\stackrel{\mathbb{Q}}{\Omega}$ for recurrence of the defect had excellent or good results. 
T A B L E V

LONG-TERM FOLLOW-UP RESULTS

( $60 \%$ of the cases were followed up for more than five years)

\begin{tabular}{|c|c|c|c|c|c|c|c|c|}
\hline \multirow{3}{*}{$\begin{array}{l}\text { Follow-up } \\
\text { (years) }\end{array}$} & \multirow{3}{*}{$\begin{array}{l}\text { No. of } \\
\text { Cases }\end{array}$} & \multicolumn{6}{|c|}{ Results } & \multirow{3}{*}{$\begin{array}{l}\text { Second } \\
\text { Operation }\end{array}$} \\
\hline & & \multicolumn{2}{|c|}{ Excellent } & \multicolumn{2}{|c|}{ Good } & \multicolumn{2}{|c|}{ Poor } & \\
\hline & & No. & $\%$ & No. & $\%$ & No. & $\%$ & \\
\hline $\begin{array}{c}1-3 \\
4-6 \\
7-10 \\
\text { More than } 10\end{array}$ & $\begin{array}{l}18 \\
16 \\
23 \\
15\end{array}$ & $\begin{array}{r}13 \\
15 \\
17 \\
8\end{array}$ & $\begin{array}{l}72 \\
94 \\
74 \\
53\end{array}$ & $\begin{array}{l}1 \\
1 \\
5 \\
5\end{array}$ & $\begin{array}{r}6 \\
6 \\
22 \\
33\end{array}$ & $\begin{array}{l}4 \\
0 \\
1 \\
2\end{array}$ & $\begin{array}{r}22 \\
0 \\
4 \\
14\end{array}$ & 3 \\
\hline Total & 72 & 53 & 73 & 12 & 17 & 7 & 10 & 3 \\
\hline
\end{tabular}

\section{REFERENCES}

Abrams, L. D. (1961). Operative treatment of funnel chest. Acta chirurgica Belgica, Suppl. 2, p. 11.

Adkins, P. C. and Blades, B. (1961). A stainless steel strut for correction of pectus excavatum. Surgery, Gynaecology and Obstetrics, 113, 111.

Borgeskov, S. and Raahave, D. (1971). Long-term result after operative correction of funnel chest. Thorax, 26, 74.

Brodkin, H. A. (1953). Congenital anterior chest wall deformities of diaphragmatic origin. Disease of the Chest, 24, 259.

Chin, E. F. (1957). Surgery of funnel chest and congenital sternal prominence. British Journal of Surgery, 44, 360.

Haller, J. A., Peters, G. N., Mazur, D., and White, J. (1970). Pectus excavatum. A 20 year surgical experience. Journal of Thoracic and Cardiovascular Surgery, 60, 375.

Jensen, N. K., Schmidt, W. R., and Garamella, J. J. (1962). Funnel chest: a new corrective operation. Journal of Thoracic and Cardiovascular Surgery, 43, 731.

$-\frac{}{-}$, and $-(1970)$. Pectus excavatum and correction. Journal of Paediatric Surgery, 5, 4.

Johnson, L. P. (1972). Criteria for the management of moderate funnel chest deformities in children. American Surgeon, 38, 498.

Lam, C. R. and Brinkman, G. L. (1959). Indications and results of the surgical treatment of pectus excavatum. Archives of Surgery, 78, 322. le Roux, B. T. (1964). Maintenance of chest wall stability. Thorax, 19, 397.

May, A. M. (1961). Operation for pectus excavatum using stainless steel wire mesh. Journal of Thoracic and Cardiovascular Surgery, 42, 122.

Moghissi, K. (1964). Long-term results of surgical correction of pectus excavatum and sternal prominence. Thorax, 19, 350.

Mullard, K. (1967). Observations on the aetiology of pectus excavatum and other chest deformities, and a method of recording them. British Journal of Surgery, 54, 115.

Peters, R. M. and Johnson, G. (1964). Stabilization of pectus deformity with wire strut. Journal of Thoracic and Cardiovascular Surgery, 47, 814.

Ravitch, M. M. (1949). The operative treatment of pectus excavatum. Annals of Surgery, 129, 429.

(1965). Technical problems of the operative correction of pectus excavatum. Annals of Surgery, 162, 29.

Wada, J. and Ikeda, K. (1972). Clinical experience with 306 funnel chest operations. International Surgery, 57, 707.

Wooler, G. H., Mashhour, Y., Garcia, J. B., Holden, M. P., and Ionescu, M. I. (1969). Pectus excavatum. Thorax, 24, 557.

Requests for reprints to: I. K. R. McMillan, F.R.C.S., Consultant Thoracic Surgeon, Southampton Western Hospital, Wessex Regional Cardiac and Thoracic Unit, Oakley Road, Millbrook, Southampton SO9 4WQ. 